\title{
Hepatic resection provided long-term survival for patients with intermediate and advanced-stage resectable hepatocellular carcinoma
}

Wei Liu, Kun Wang, Quan Bao, Yi Sun and Bao-Cai Xing ${ }^{*}$

\begin{abstract}
Background: Hepatic resection has the highest local controllability that results in long-term survival for hepatocellular carcinoma (HCC). This study aimed to investigate the role of hepatic resection in selected patients of intermediate and advanced stage.

Methods: Clinical, pathological, and outcome data of 542 consecutive patients were retrospectively analyzed from a single center. The Kaplan-Meier method was used to estimate survival. Postoperative prognostic factors were evaluated using univariate and multivariate analyses.

Results: The 1-, 3-, and 5-year overall survival rates were 89.0, 64.3, and 53.0 \%, respectively. The 1-, 3-, and 5-year disease-free survival rates were $72.2,44.5$, and $34.2 \%$, respectively. Preoperative a-fetoprotein level $>400 \mathrm{ng} / \mathrm{mL}$, macroscopic vascular invasion, microscopic portal vein thrombosis, multiple tumor nodules, and the largest tumor size $>5 \mathrm{~cm}$ were significantly correlated with overall survival. When these clinical risk factors were used in a postoperative staging system, assigning one point for each factor, the total score was precisely predictive of long-term survival. For patients with surgery plus adjuvant TACE (transarterial chemoembolization), the median overall survival was 56 months (range 1-110 months) and the 5-year OS rate was $48.5 \%$.
\end{abstract}

Conclusions: Hepatic resection is efficient and safe for HCC patients of intermediate and advanced stage.

The adjuvant TACE should be recommended for HCC patients with poor risk factors.

Keywords: Hepatocellular, Hepatic resection, Prognosis, Large, Multinodular

\section{Background}

Worldwide, hepatocellular carcinoma, the most common primary cancer of the liver, ranks sixth among malignant tumors in incidence and is the third leading cause of cancer-related death [1]. In China, owing to the high prevalence of hepatitis B viral infection and associated liver cirrhosis, hepatocellular carcinoma (HCC) accounts for more than $54 \%$ of the world annual incidence, with an estimated 372,079 mortalities [2, 3].

\footnotetext{
* Correspondence: xingbaocai88@sina.com

Hepatopancreatobiliary Surgery Department I, Key Laboratory of

Carcinogenesis and Translational Research, Ministry of Education, Peking

University School of Oncology, Beijing Cancer Hospital and Institute, No. 52

Fu-Cheng-Lu Street, Beijing 100142, People's Republic of China
}

Hepatic resection is considered as the first-line therapeutic option for HCC among all treatments [4]. Liver transplantation has the highest potential to cure because of its ability to remove at once both the seeded HCC and the damaged hepatic tissue $[5,6]$. Milan criteria (single $\mathrm{HCC} \leq 5 \mathrm{~cm}$ or three $\mathrm{HCC} \leq 3 \mathrm{~cm}$ each) showed a 4-year survival of $75 \%$ [7]. The prognosis for patients with HCC remains discouraging due to the recurrence of $\mathrm{HCC}$ which is the main problem postoperatively and the 5-year overall survival rate which is only 34 to $50 \%$ [8]. Many risk factors are known to be closely associated with a poor long-term outcome of survival [9]. The Barcelona Clinic Liver Cancer (BCLC) staging classification is widely adopted because it is the only staging system that links prognostic classification to treatment 
indications [10]. However, tumor size larger than $5 \mathrm{~cm}$ and macroscopic vascular invasion were regarded as contraindications for hepatic resection.

This article aims to explore the factors that indicate prognosis of HCC patients included in selected intermediate and advanced stage. The effect of adjuvant TACE (transarterial chemoembolization) in patients with poor risk factors was also investigated. The present study was based on a prospective database and retrospective analysis on the common parameters of 542 patients from a single center.

\section{Methods}

\section{Study population}

Between January 2005 and December 2013, 549 consecutive HCC patients underwent radical hepatic resection at the Hepatopancreatobiliary Surgery Department I of Peking University Cancer Hospital. The diagnoses of HCC were all confirmed by histopathology.

\section{Preoperative evaluation}

Before surgery, several routine tests, including complete blood count, a liver function panel (alanine aminotransferase [ALT], aspartate aminotransferase [AST], total bilirubin [TBIL], albumin [ALB], and so forth), a coagulation panel (prothrombin time [PT], activated partial thromboplastin time, and so forth), and alpha-fetoprotein (AFP) were required for each patient. The patients also were tested for hepatitis virus infection. Chest radiography was taken to exclude pulmonary metastasis. Abdominal ultrasonography, computed tomography, and/or magnetic resonance imaging were applied to assess tumor resectability.

\section{Definition of BCLC stage and resectable $\mathrm{HCC}$}

The BCLC stage is described as follows. Stage 0 includes single tumors smaller than $2 \mathrm{~cm}$ in diameter. Stage A includes single tumors smaller than $5 \mathrm{~cm}$ in diameter or up to three tumors all smaller than $3 \mathrm{~cm}$ in diameter. Stage B includes up to three tumors ( 1 of which is $>3 \mathrm{~cm}$ in diameter) or more than three tumors of any size. Single tumors exceeding $5 \mathrm{~cm}$ in diameter are included in this stage based on the article by Bruix and Llovet. Stage $\mathrm{C}$ includes macrovascular invasion (major portal or hepatic veins). Alternatively, stage $C$ involves lymph node metastases or distant metastases. Resectable HCC consists of Child-Pugh stages A and B patients with any size single resectable tumor or multifocal tumor which was defined as two to three tumors exceeding $3 \mathrm{~cm}$ in maximal diameter, in the absence of cancer-related symptoms, main trunk of portal vein invasion, and/or extra-hepatic spread [11].

\section{Hepatic resection and adjuvant TACE}

All patients underwent hepatic resection with curative intent, as well as achieve R0, preserving as much normal functional liver parenchyma (with adequate vascular inflow, outflow, and biliary drainage) as possible. Resection of three or more segments was considered a major hepatic resection. The normal liver parenchyma remnant volume was more than $30 \%$. For the liver cirrhosis patients, the remnant volume should be preserved more than $40 \%$ [12]. There was no patient who underwent liver transplantation. Four to six weeks after hepatic resection, the patient with good general condition and normal liver function received the first course of interventional therapy. Adjuvant TACE was defined as patients who chose TACE as adjuvant treatment after hepatic resection 1 month and repeated every 4 weeks for more than two consecutive courses. A combination regimen of epirubicin, calcium folinate, oxaliplatin, and fluorouracil would be administered. Informed consent signed by every patient before treatment and approval of the Institutional Ethics Committee were obtained.

\section{Follow-up evaluation}

All patients were followed up every 3 months for the first 2 years, with a physical examination, liver function tests, levels of AFP, chest radiography, and abdominal ultrasonography. Every 6 months, the patients would undergo computed tomography (CT) scan and/or MRI. The last follow-up evaluation was censored on February 1,2015 , or up to the time of death.

\section{Statistics}

Continuous variables were summarized as a mean, and categorical variables were summarized as frequency and percentage. Statistical comparison between qualitative variables was performed with the Pearson chi-square test. Kaplan-Meier survival was calculated from the date of hepatic resection, and significant differences were determined with a log-rank test. Univariate and multivariate analyses of various clinicopathological factors by Cox's proportional hazard model were used to identify independent risk factors for overall survival. The linear regression was performed to describe the predictors of long-term survival. All $p$ values were based on a twosided test of statistical significance. Significance was accepted at $p<0.05$. Statistical analysis was performed using SPSS 19.0 (SPSS, Inc., Chicago, IL, USA).

\section{Results}

\section{Patients characteristic}

Between January 2005 and December 2013, 549 patients who underwent surgical resection were investigated. Seven $(1.3 \%)$ patients were lost in the follow-up. Therefore, 542 patients were enrolled. It included 458 male 
and 84 female patients, with a median age of 56 years (range 27-88). The mean TBIL was $15.7 \pm 6.9 \mu \mathrm{mol} / \mathrm{L}$ (range $2-48$, median $14.7 \mu \mathrm{mol} / \mathrm{L}$ ). The mean ALB was $43.55 \pm 4.7 \mathrm{~g} / \mathrm{L}$ (range $31-56$, median $43.75 \mathrm{~g} / \mathrm{L}$ ). The mean PT was $12.5 \pm 1.46 \mathrm{~s}$ (range 9-17, median $12 \mathrm{~s}$ ). The mean preoperative AFP level was $227.12 \pm 118.21 \mathrm{ng} / \mathrm{mL}$ (range 1-1018, median $118 \mathrm{ng} / \mathrm{mL}$ ) (Table 1).

\section{Surgery details and early postoperative outcome}

A major hepatic resection was performed in 144 (26.57 \%) patients. According to the Clavien-Dino classification system, 86 patients underwent minor complications (Clavien grade $<3$ ) (Table 1). There were 17 patients with PT $>14 \mathrm{~s}$. No liver failure happened to them. Only one of them suffered from transient diarrhea after hepatic resection.

\section{Pathological results and prognostic factors for overall survival}

The mean tumor size was $5.27 \pm 3.28 \mathrm{~cm}$ (range 0.5-19, median $4.5 \mathrm{~cm}$ ). Multiple tumor nodules but $\leq 3$ was detected in 66 (12.18\%) patients. Microscopic portal vein thrombosis was detected in $143(26.38 \%)$ patients. Macroscopic vascular invasion was detected in 54 (9.96 \%) patients (Table 1). Overall survival was influenced by preoperative AST level $(p=0.001)$, AFP level $(p=0.009)$, the largest tumor size $(p<0.001)$, multiple tumor nodules $(p<0.001)$, microscopic portal vein thrombosis $(p<$ $0.001)$, macroscopic vascular invasion $(p<0.001)$, blood lose $(p=0.042)$, blood transfusion $(p<0.001)$, and type of hepatic resection $(p<0.001)$ in univariate analysis. Multivariate analysis showed that preoperative AFP $(p=$ $0.010)$, the largest tumor size $>5 \mathrm{~cm}(p<0.001)$, multiple tumor nodules $(\leq 3)(p<0.001)$, microscopic portal vein

Table 1 Patients and tumor characteristics

\begin{tabular}{|c|c|}
\hline Variable & No. of patients \\
\hline \multicolumn{2}{|l|}{ Patients demographics } \\
\hline Gender (male/female) & 458 (84.5 \%)/84 (15.5 \%) \\
\hline ECOG $(0 / 1 / 2)$ & $312(57.6 \%) / 170$ (31.4 \%)/60 (11\%) \\
\hline Age (year) ( $\leq 60$ vs. $>60$ years) & $361(66.6 \%) / 181$ (33.4 \%) \\
\hline Hepatitis B (+/-) & $421(77.7 \%) / 118$ (22.3 \%) \\
\hline Hepatitis C (+/-) & $39(7.2 \%) / 503(92.8 \%)$ \\
\hline AFP level ( $\leq 400$ vs. $>400$ ng/mL) & $414(76.4 \%) / 128$ (23.6 \%) \\
\hline ALT level ( $\leq 40$ vs. $>40 \mathrm{U} / \mathrm{L})$ & $350(64.6 \%) / 192(35.4 \%)$ \\
\hline AST level ( $\leq 40$ vs. $>40 \mathrm{U} / \mathrm{L})$ & $331(61.1 \%) / 211$ (38.9 \%) \\
\hline TBIL level ( $\leq 17.5$ vs. $>17.5 \mathrm{~mol} / \mathrm{L})$ & $356(65.7 \%) / 186(34.3 \%)$ \\
\hline ALB level ( $\leq 35$ vs. $>35 \mathrm{~g} / \mathrm{L})$ & $22(4.1 \%) / 520(95.9 \%)$ \\
\hline $\mathrm{PT}(\leq 14$ vs. $>14 \mathrm{~s})$ & $525(96.9 \%) / 17(3.1 \%)$ \\
\hline Liver cirrhosis (+) & $390(72.0 \%) / 150(28.0 \%)$ \\
\hline \multicolumn{2}{|l|}{ Tumor characteristics } \\
\hline Tumor size ( $\leq 5$ vs. $>5$ ) & $325(60.0 \%) / 217(40.0 \%)$ \\
\hline No. of tumor (single vs. multiple) & $473(87.3 \%) / 69(12.7 \%)$ \\
\hline Microscopic portal vein thrombosis $(+/-)$ & $143(26.4 \%) / 399(73.6 \%)$ \\
\hline Macroscopic vascular invasion (+/-) & $54(10.0 \%) / 488$ \\
\hline \multicolumn{2}{|l|}{ Surgery details } \\
\hline Operation time (min) & $148 \pm 55.6$ \\
\hline Blood lose ( $\leq 1000$ vs. $>1000 \mathrm{~mL}$ ) & $506(93.4 \%) / 36(6.6 \%)$ \\
\hline Blood transfusion $(n)$ & 60 (11.1\%) \\
\hline Type of liver resection (minor vs. major) & $398(73.4 \%) / 144$ (26.6 \%) \\
\hline \multicolumn{2}{|l|}{ Complications } \\
\hline Minor (Clavien grade <3) & $86(15.9 \%)$ \\
\hline Major (Clavien grade $\geq 3$ ) & $23(4.2 \%)$ \\
\hline Hospital stay (day) & $13.8 \pm 11.6$ \\
\hline Child-Pugh grade (A/B) & $538(99.3 \%) / 4(0.7 \%)$ \\
\hline $\mathrm{BCLC}$ stage $(0 / \mathrm{A} / \mathrm{B} / \mathrm{C})$ & $76(14.0 \%) / 208(38.4 \%) / 204(37.6 \%) / 54(10 \%)$ \\
\hline
\end{tabular}


thrombosis $(p=0.014)$, and macroscopic vascular invasion $(p=0.017)$ were the independent prognostic factors for poor OS (Table 2).

\section{Survival analysis}

The median follow-up was 69 months (range 1111 months). Seven (1.29 \%) patients were lost in the follow-up. Cancer in 305 (56.27 \%) patients recurred after surgery, and 206 (38.01\%) of them died of cancer recurrence. The 1-, 3-, and 5-year disease-free survival
(DFS) rates were $72.2,44.5$, and $34.2 \%$, respectively The 1-, 3-, and 5-year overall survival (OS) rates were 89.0, 64.3 , and $53.0 \%$, respectively (Fig. 1). According to the BCLC staging system, the 5-year OS rate for BCLC stages $0, \mathrm{~A}, \mathrm{~B}$, and $\mathrm{C}$ was $72.4,66.3,36.9$, and $28.9 \%$, respectively $(p<0.001)$ (Fig. 2$)$. The five clinical risk factors that are preoperative AFP level $>400 \mathrm{ng} / \mathrm{mL}$, the largest tumor size $>5 \mathrm{~cm}$, multiple tumor nodules, macroscopic vascular invasion, and microscopic portal vein thrombosis were chosen. The more risk factors

Table 2 Prognostic factors of overall survival and disease-free survival

\begin{tabular}{|c|c|c|c|c|c|c|}
\hline \multirow[b]{2}{*}{ Analysis } & \multicolumn{3}{|l|}{ OS } & \multicolumn{3}{|l|}{ DFS } \\
\hline & OR & $95 \% \mathrm{Cl}$ & $p$ value & OR & $95 \% \mathrm{Cl}$ & $p$ value \\
\hline \multicolumn{7}{|l|}{ Univariate } \\
\hline Male sex & 1.092 & $0.741-1.609$ & 0.653 & 0.975 & $0.716-1.328$ & 0.873 \\
\hline Age $>60$ years & 0.848 & $0.633-1.135$ & 0.263 & 0.934 & $0.737-1.185$ & 0.572 \\
\hline ECOG $(0 / 1 / 2)$ & 0.681 & $0.426-1.112$ & 0.752 & 0.704 & $0.421-1.191$ & 0.726 \\
\hline Child-Pugh A/B & 3.123 & $0.995-9.800$ & 0.099 & 1.780 & $0.570-5.560$ & 0.364 \\
\hline $\operatorname{HBV}(+)$ & 1.050 & $0.754-1.463$ & 0.772 & 1.140 & $0.863-1.505$ & 0.350 \\
\hline $\mathrm{HCV}(+)$ & 1.142 & $0.695-1.876$ & 0.608 & 1.174 & $0.773-1.782$ & 0.462 \\
\hline AST $>40 \mathrm{U} / \mathrm{L}$ & 1.592 & $1.209-2.096$ & 0.001 & 1.528 & $1.217-1.919$ & $<0.001$ \\
\hline $\mathrm{ALT}>40 \mathrm{U} / \mathrm{L}$ & 1.142 & $0.866-1.506$ & 0.348 & 1.192 & $0.949-1.496$ & 0.133 \\
\hline $\mathrm{TBIL}>17.5 \mathrm{~mol} / \mathrm{L}$ & 0.789 & $0.584-1.066$ & 0.117 & 0.854 & $0.671-1.086$ & 0.194 \\
\hline$A L B \leq 35 \mathrm{~g} / \mathrm{L}$ & 1.154 & $0.628-2.119$ & 0.651 & 1.422 & $0.859-2.353$ & 0.239 \\
\hline PT $>14 \mathrm{~s}$ & 2.012 & $1.064-3.803$ & 0.052 & 2.191 & $0.780-3.753$ & 0.401 \\
\hline AFP $>400 \mathrm{ng} / \mathrm{mL}$ & 1.516 & $1.118-2.057$ & 0.009 & 1.434 & $1.113-1.847$ & 0.007 \\
\hline Liver cirrhosis (+) & 0.890 & $0.658-1.204$ & 0.450 & 1.030 & $0.798-1.329$ & 0.821 \\
\hline Tumor size $>5 \mathrm{~cm}$ & 2.925 & $2.212-3.867$ & $<0.001$ & 1.904 & $1.518-2.388$ & $<0.001$ \\
\hline Microscopic portal vein $(+)$ & 2.281 & $1.714-3.035$ & $<0.001$ & 1.825 & $1.432-2.325$ & $<0.001$ \\
\hline Macroscopic vascular invasion (+) & 2.819 & $1.963-4.048$ & $<0.001$ & 2.228 & $1.616-3.082$ & $<0.001$ \\
\hline Multiple nodes but $\leq 3$ & 2.818 & $1.975-4.058$ & $<0.001$ & 2.486 & $1.823-3.390$ & $<0.001$ \\
\hline Blood loss >1000 mL & 1.649 & $1.049-2.591$ & 0.042 & 1.032 & $0.618-1.641$ & 0.327 \\
\hline Blood transfusion $(+)$ & 3.310 & $2.402-4.561$ & $<0.001$ & 1.229 & $0.712-1.548$ & 0.614 \\
\hline Complications (+) & 1.254 & $0.937-1.679$ & 0.133 & 1.439 & $1.130-1.832$ & 0.003 \\
\hline Major liver resection & 2.475 & $1.854-3.258$ & $<0.001$ & 1.941 & $1.528-2.465$ & $<0.001$ \\
\hline Adjuvant TAC/TACE & 1.132 & $0.683-2.126$ & 0.627 & 0.134 & $0.512-1.168$ & 0.079 \\
\hline \multicolumn{7}{|l|}{ Multivariate } \\
\hline $\mathrm{AST}>40 \mathrm{U} / \mathrm{L}$ & 1.044 & $0.722-1.510$ & 0.818 & 0.860 & $0.611-1.209$ & 0.385 \\
\hline AFP $>400 \mathrm{ng} / \mathrm{mL}$ & 1.523 & $1.107-2.095$ & 0.010 & 1.213 & $0.922-1.598$ & 0.168 \\
\hline Tumor size $>5 \mathrm{~cm}$ & 2.002 & $1.443-2.778$ & $<0.001$ & 1.489 & $1.129-2.078$ & 0.013 \\
\hline Microscopic portal vein $(+)$ & 1.559 & $1.126-2.159$ & 0.007 & 1.266 & $0.967-1.657$ & 0.086 \\
\hline Macroscopic vascular invasion (+) & 1.655 & $1.096-2.499$ & 0.017 & 0.982 & $0.672-1.435$ & 0.926 \\
\hline Multiple nodes but $\leq 3$ & 2.134 & $1.460-3.120$ & $<0.001$ & 0.888 & $0.636-1.239$ & 0.484 \\
\hline Blood loss >1000 mL & 1.142 & $0.708-1.842$ & 0.585 & 1.073 & $0.696-1.654$ & 0.749 \\
\hline Blood transfusion & 1.025 & $0.686-1.531$ & 0.904 & 1.238 & $0.945-1.621$ & 0.121 \\
\hline Major liver resection & 1.348 & $0.964-1.887$ & 0.081 & 1.100 & $0.836-1.449$ & 0.495 \\
\hline Complications & & & & 1.136 & $0.877-1.472$ & 0.333 \\
\hline
\end{tabular}




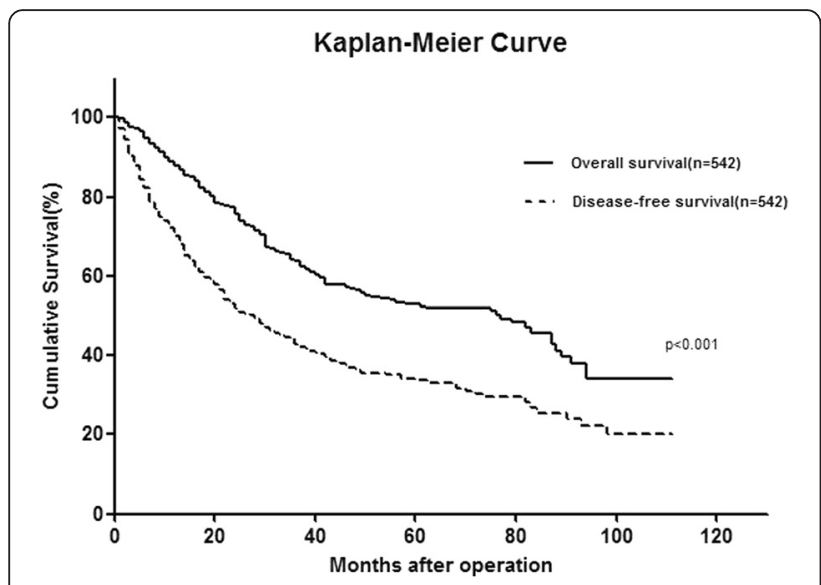

Fig. 1 Kaplan-Meier curve showing OS and DFS for 542 HCC patients

accumulated, the poorer the prognosis of the patient is. The 5-year overall survival rate of risk factors $0,1,2,3$ and 4 was $72.9,60.8,30.8,11.7$, and $8.6 \%$, respectively (Additional file 1: Figure S1).

\section{Adjuvant TACE for patients with risk factors}

Among the patients with clinical risk factors that are independent prognostic factors for poor OS in multivariate analysis, 162 underwent adjuvant TACE. There was no significant difference in clinical characteristics of patients. Patients in adjuvant TACE group had smooth recovery after treatment. No serious complication or hospital death occurred (Additional file 2: Table S1). For patients with surgery plus adjuvant TACE, the median DFS was 23 months (range 1-110 months), and the 5year DFS rate was $33.0 \%(n=162)$. It differs significantly from the patients with surgery alone $(n=205)$. The median DFS was 21 months (range 1-75 months), and the 5 -year DFS rate was $21.6 \%(p=0.033)$ (Additional file 3:

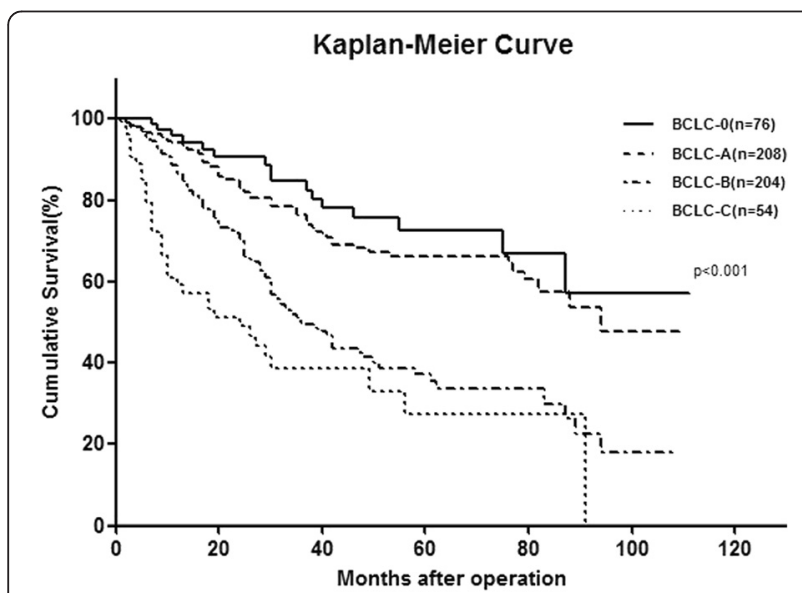

Fig. 2 Kaplan-Meier curve showing OS according to BCLC stage for 542 HCC patients
Figure S2A). For patients with surgery plus adjuvant TACE, the median OS was 56 months (range 1110 months) and the 5-year OS rate was $48.5 \%$. It differs significantly from the patients with surgery alone. The median OS was 35 months (range 1-88 months), and the 5 -year OS rate was $38.7 \%(p=0.016)$ (Additional file 3: Figure S2B).

\section{Literature review}

A total of 24 eligible studies were found to satisfy the inclusion criteria, and the key demographic and clinicopathological data were extracted (Table 3). Studies were organized into subgroups depending on whether they involved large and/or multinodular HCC [13-29] (BCLC stage B) and HCC with macrovascular invasion [30-36] (BCLC stage C). The majority of the studies reported hospital mortality less than $11.1 \%$. The overall survival after hepatic resection were 45 to $99 \%$ (1 year), 17 to $84.2 \%$ ( 3 years), and $10 \%$ to $65 \%$ (5 years).

\section{Discussion}

The present study containing 542 consecutive patients represents an institutional review of surgical resection as the initial primary therapy for HCC from tertiary referral hospital. In the present study, factors that resulted in poor long-term outcomes after hepatic resection were identified, including preoperative AFP level, macroscopic vascular invasion, the largest tumor size $>5 \mathrm{~cm}$, multiple tumor nodules, and microscopic portal vein. These factors objectively predict the long-term outcome of the resectable HCC: the more risk factors accumulated, the poorer the prognosis is.

More than $70 \%$ of HCC patients have AFP secretion, and a high serum level of AFP ( $>400 \mathrm{ng} / \mathrm{mL})$ may be an indirect measure of tumor burden [37]. The prognostic significance of AFP also has been testified in multiple studies [38]. Multiple tumor nodules were considered to be a poor factor of survival [39]. Multifocal hepatocellular carcinoma (HCC) may be multiple HCCs of multicentric origin (MO) or intrahepatic metastases (IM) arising from a primary HCC. Numerous attempts to differentiate the two types of multifocal HCC have been made due to the different prognosis of two types [40]. Tumor larger than $5 \mathrm{~cm}$ was an important indicator of a high risk of recurrence, a higher incidence of intrahepatic metastasis and portal venous invasion [41]. It was classified into BCLC B stage, which correlated with a high risk of intraoperative blood loss and postoperative liver failure, leading them to be against HR for HCC outside the Milan criteria [42]. Macroscopic vascular invasion was classified into stage $C$ that sorafenib was recommended as treatment [42]. Therefore, hepatic resection is not recommended as the first-line treatment 
Table 3 Outcomes of hepatic resection for patients with BCLC stage B/C HCC in literature review

\begin{tabular}{|c|c|c|c|c|c|c|c|c|c|}
\hline \multirow[t]{2}{*}{ Study } & \multirow[t]{2}{*}{ Patient origins } & \multirow{2}{*}{$\begin{array}{l}\text { Recruitment } \\
\text { period }\end{array}$} & \multirow[t]{2}{*}{ Number } & \multirow{2}{*}{$\begin{array}{l}\text { HCC } \\
\text { characteristics }\end{array}$} & \multirow{2}{*}{$\begin{array}{l}\text { Hospital } \\
\text { mortality } \\
(\%)\end{array}$} & \multirow{2}{*}{$\begin{array}{l}\text { Median } \\
\text { survival } \\
\text { (month) }\end{array}$} & \multicolumn{3}{|c|}{ Overall survival } \\
\hline & & & & & & & 1 year & 3 years & 5 years \\
\hline \multicolumn{10}{|c|}{ Single, large, and/or multinodular HCC } \\
\hline Cheng et al. [13] & Taiwan & 1999-2005 & 104 & $>5 \mathrm{~cm}$ & 7.3 & - & 90 & - & 66 \\
\hline Heng-Jun et al. [14] & China & 2000-2009 & 151 & $\mathrm{BCLC} B$ & - & 61.8 & 99 & 68 & 52 \\
\hline Ho et al. [15] & Taiwan & $1981-2000$ & 294 & $\mathrm{BCLC} B$ & - & 37.9 & 77.4 & 51.9 & 36.6 \\
\hline Hsu et al. [16] & Taiwan & $2002-2010$ & 268 & $\mathrm{BCLC} B+\mathrm{C}$ & 2.7 & - & 81 & 63 & 43 \\
\hline Jin et al. [17] & South Korea & 1998-2013 & 62 & $\mathrm{BCLC} B$ & 11.1 & - & 83.2 & 75.7 & 65 \\
\hline Jianyong et al. [18] & China & $2002-2008$ & 433 & $\mathrm{BCLC} B$ & 2.3 & - & 91.8 & 84.2 & 70.8 \\
\hline Lee et al. [19] & Korea & 1997-2003 & 100 & $>10 \mathrm{~cm}$ & 2.0 & - & 66 & 44 & 31 \\
\hline Lim et al. [20] & Japan & 1994-2010 & 172 & $>5 \mathrm{~cm}$ & 1 & - & - & - & 58 \\
\hline Lin et al. [21] & Taiwan & 2001-2007 & 93 & $\mathrm{BCLC} B$ & 5.4 & $29.9 \pm 20.1$ & 83 & 49 & - \\
\hline $\mathrm{Ng}$ et al. [22] & Asia, Europe, USA & $1982-2001$ & 380 & $>5 \mathrm{~cm}$ & 2.7 & - & 74 & 50 & 39 \\
\hline Nojiri et al. [23] & Japan & 1992-2011 & 107 & $>5 \mathrm{~cm}$ & - & - & - & 62 & 38.1 \\
\hline Pandey et al. [24] & Singapore & 1995-2006 & 166 & $>10 \mathrm{~cm}$ & 3.0 & - & - & - & 29 \\
\hline Poon et al. [25] & Hong Kong & $1991-2000$ & 120 & $>10 \mathrm{~cm}$ & 5.0 & - & 61 & 38 & 28 \\
\hline Wang et al. [26] & Taiwan & 1986-2002 & 243 & $\mathrm{BCLC} B$ & - & $60.4 \pm 6.1$ & 81.5 & 64.4 & 50.5 \\
\hline Yin et al. [27] & China & 2008-2010 & 88 & $\mathrm{BCLC} B$ & 11.3 & 41 & 76.1 & 51.5 & - \\
\hline Zhong et al. [28] & China & $2000-2010$ & 660 & $\mathrm{BCLC} B$ & 2.6 & - & 91 & 67 & 44 \\
\hline Zhong et al. [29] & China & 2000-2007 & 257 & $\mathrm{BCLC} B$ & 3.1 & $42.9 \pm 26.1$ & 84 & 59 & 37 \\
\hline \multicolumn{10}{|c|}{ Macrovascular invasion HCC } \\
\hline Chang et al. [30] & Taiwan & $1991-2006$ & 160 & $\mathrm{BCLC} C$ & 2.7 & - & 58 & 34 & 29 \\
\hline Huang et al. [31] & China & 1998-2008 & 116 & $>15 \mathrm{~cm}$ & 3.4 & - & 71 & 23 & 11 \\
\hline Ikai et al. [32] & Japan & 1992-2003 & 976 & $\mathrm{BCLC} C$ & 2.5 & - & 50 & 26 & 18 \\
\hline Pawlik et al. [33] & Asia, Europe, USA & 1984-1999 & 102 & $\mathrm{BCLC} C$ & 5.9 & - & 45 & 17 & 10 \\
\hline Shi et al. [34] & China & $2001-2003$ & 406 & $\mathrm{BCLC} C$ & 0.2 & - & 34 & 13 & - \\
\hline Torzilli et al. [35] & China, Europe, USA & 1990-2009 & 297 & $\mathrm{BCLC} C$ & 3.0 & - & 76 & 49 & 38 \\
\hline Yang et al. [36] & China & 2001-2007 & 511 & $\mathrm{BCLC} C$ & 3.0 & - & 70 & 41 & 31 \\
\hline
\end{tabular}

for single large, multinodular, and macrovascular invasion HCCs according to the BCLC stage system.

However, the BCLC staging classification was based on a 15-year-old study and drew its conclusion from the prognostic analysis of HCC patients who were predominantly $\mathrm{HCV}$ infected and received curative treatment. This staging may not reflect cancer progression or prognosis in HCC patients for whom HBV infection is the predominant etiological factor [42]. HBV-associated HCC generally exhibit a better preserved liver function than $\mathrm{HCV}$ associated patients. As a result of recent advances in surgical techniques and preoperative management, the indications for hepatic resection have expanded, and hepatic resection has become a reasonably safe treatment option with an acceptable mortality rate [43]. Studies have testified that if patients had preserved liver function, hepatic resection still achieved better survival results than other treatments for BCLC B stage [15, 44]. Actually, the intermediate and advanced stage of HCC comprises a highly heterogeneous population, in that patients may differ according to tumor load, age, liver function, and possible comorbidities, which fall under BCLC stages $B$ and $C$ and can vary greatly. According to this study, the extension of hepatic resection was related to blood loss in operation and morbidity of biliary fistula, which increased the length of hospital stay but the complication was not independently correlated to the survival of HCC. Nevertheless, studies from both the West and the East clearly have shown that surgical resection could be performed safely and led to long-term survival in these subsets of HCC patients [32, 33]. In the present study, the 5-year OS rate for BCLC stages $0, A, B$ and $C$ was $72.4,66.3,36.9$, and $28.9 \%$, respectively $(p<0.001)$, which is in accordance with previous reports.

The main effects of postoperative TACE on HCC are the following: to inhibit remnant tumor growth, detect it early, and to treat tiny metastases [45]. The concentration of chemotherapeutics within tumor tissue can be 
achieved 10-100 times higher than systemic therapy [46]. It was usually believed that multi-intrahepatic tumor and portal vein tumor thrombosis could not be totally removed. The patient with such risk factors is recommended to receive TACE 1-2 months after resection [47].

Treatment decision of HCC should be based on a multidisciplinary interaction between different specialists [6]. This approach necessitates the involvement of multiple specialists to provide individualized treatment strategies. Guidelines, although useful, must be adapted to the advances of HCC [48]. BCLC B and C HCC might benefit from perioperative treatment including the control of portal hypertension, reduction of tumor burden, and virosuppression of hepatitis [49]. Combined to these multiple individualized treatment strategies, in most Asian centers owing to higher case volume and expertise, it was well recognized that a more aggressive treatment approach has been adopted [50].

\section{Limitation}

There were several limitations of this study. First, the present study was retrospective in nature and without control group. It thus was subject to potential bias that might prevent definite conclusions to be drawn. Second, it will be of interest to evaluate how our staging system compares with the BCLC staging in a Western HCC patient population because the more aggressive treatment guidelines may yield a better survival outcome in nonAsian HCC patients as well. Third, hepatic resection was performed only on patients with no more than three nodules. For four or more tumors, TACE or other palliative care was recommended [11]. Therefore, the patients enrolled in present study were limited to patients with no more than three nodules. Finally, there is no further validation which should be performed in the future.

\section{Conclusions}

Hepatic resection is efficient and safe for HCC patients of intermediate and advanced stage. The adjuvant TACE should be recommended for HCC patients with poor risk factors.

\section{Additional files}

Additional file 1: Figure S1. Kaplan-Meier curve showing overall survival of clinical risk factors. The more risk factors accumulated, the poorer the prognosis of the patient is. (JPG 396 KB)

Additional file 2: Table S1. Characteristics of Patients with Risk Factors. (DOCX 514 KB)

Additional file 3: Figure S2. Kaplan-Meier Curve showing DFS of surgery plus TACE and surgery alone. (ZIP 396 KB)

\section{Competing interests}

The authors declare that they have no competing interests.

\section{Authors' contributions}

$W L$ and $B C X$ participated in the study concepts and study design. WL, KW, and $\mathrm{QB}$ participated in the data acquisition and statistical analysis. WL, YS, and BCX participated in the quality control of data and algorithms. WL and YS participated in the data analysis and interpretation. WL and BCX participated in the manuscript preparation. WL and KW participated in the manuscript editing. WL, QB, YS, and BCX participated in the manuscript review. All authors read and approved the final manuscript.

\section{Acknowledgements}

We acknowledge Hong-Wei Wang who contributed towards the study by making substantial contributions to the acquisition of the data and Ke-Min Jin who made substantial contributions to the analysis and interpretation of the data. Both of them are involved in drafting the manuscript but do not meet the criteria for authorship. This research was supported by grants from the Chinese State Key Project for Basic Research (973) (2014CBA02001).

Received: 2 June 2015 Accepted: 17 February 2016

Published online: 02 March 2016

\section{References}

1. Jemal A, Bray F, Center MM, et al. Global cancer statistics[J]. CA Cancer J Clin. 2011;61(2):69-90.

2. Liu J, Fan D. Hepatitis B in China[J]. Lancet. 2007;369(9573):1582-3.

3. Tang ZY, Ye SL, Liu YK, et al. A decade's studies on metastasis of hepatocellular carcinoma[J]. J Cancer Res Clin Oncol. 2004;130(4):187-96.

4. Makuuchi M, Donadon M, Torzilli G. Hepatic resection for hepatocellular carcinoma in cirrhosis[J]. Ann Ital Chir. 2008;79(2):111-5.

5. Bruix J, Sherman M. Management of hepatocellular carcinoma: an update[J]. Hepatology. 2011;53(3):1020-2.

6. European Association For The Study Of The Liver; European Organisation For Research And Treatment Of Cancer. EASL-EORTC clinical practice guidelines: management of hepatocellular carcinoma[J]. J Hepatol. 2012; 56(4):908-43.

7. Mazzaferro V, Regalia E, Doci R, et al. Liver transplantation for the treatment of small hepatocellular carcinomas in patients with cirrhosis[J]. N Engl J Med. 1996;334(11):693-9.

8. Lang H, Sotiropoulos GC, Brokalaki El, et al. Survival and recurrence rates after resection for hepatocellular carcinoma in noncirrhotic livers[J]. J Am Coll Surg. 2007;205(1):27-36.

9. Yau T, Tang W, Yao TJ, et al. Development of Hong Kong Liver Cancer staging system with treatment stratification for patients with hepatocellular carcinoma[J]. Gastroenterology. 2014;146(7):1691-700.

10. Shirabe K, Kajiyama K, Abe T, et al. Predictors of microscopic portal vein invasion by hepatocellular carcinoma: measurement of portal perfusion defect area ratio[J]. J Gastroenterol Hepatol. 2009;24(8):1431-6.

11. Makuuchi M, Kokudo N. Clinical practice guidelines for hepatocellular carcinoma: the first evidence based guidelines from Japan[J]. World J Gastroenterol. 2006;12(5):828-9.

12. Aoki T, Imamura $H$, Hasegawa $K$, et al. Sequential preoperative arterial and portal venous embolizations in patients with hepatocellular carcinoma[J]. Arch Surg. 2004;139(7):766-74.

13. Cheng $\mathrm{CH}, \mathrm{Yu} \mathrm{MC}, \mathrm{Wu} \mathrm{TH}$, et al. Surgical resection of centrally located large hepatocellular carcinoma[J]. Chang Gung Med J. 2012;35(2):178-91.

14. Heng-Jun G, Yao-Jun Z, Min-Shan C, et al. Rationality and effectiveness of transarterial chemoembolization as an initial treatment for BCLC B stage HBV-related hepatocellular carcinoma[J]. Liver Int. 2014;34(4):612-20.

15. Ho MC, Huang GT, Tsang YM, et al. Liver resection improves the survival of patients with multiple hepatocellular carcinomas[J]. Ann Surg Oncol. 2009; 16(4):848-55.

16. Hsu CY, Hsia CY, Huang $\mathrm{YH}$, et al. Comparison of surgical resection and transarterial chemoembolization for hepatocellular carcinoma beyond the Milan criteria: a propensity score analysis[J]. Ann Surg Oncol. 2012; 19(3):842-9.

17. Jin YJ, Lee JW, Choi YJ, et al. Surgery versus transarterial chemoembolization for solitary large hepatocellular carcinoma of BCLC stage A[J]. J Gastrointest Surg. 2014;18(3):555-61.

18. Jianyong L, Lunan $Y$, Wentao W, et al. Barcelona clinic liver cancer stage $B$ hepatocellular carcinoma: transarterial chemoembolization or hepatic resection?[J]. Medicine (Baltimore). 2014;93(26):e180. 
19. Lee SG, Hwang S, Jung JP, et al. Outcome of patients with huge hepatocellular carcinoma after primary resection and treatment of recurrent lesions[J]. Br J Surg. 2007;94(3):320-6.

20. Lim C, Mise Y, Sakamoto $Y$, et al. Above $5 \mathrm{~cm}$, size does not matter anymore in patients with hepatocellular carcinoma[J]. World J Surg. 2014; 38(11):2910-8

21. Lin CT, Hsu KF, Chen TW, et al. Comparing hepatic resection and transarterial chemoembolization for Barcelona Clinic Liver Cancer (BCLC) stage B hepatocellular carcinoma: change for treatment of choice?[J]. World J Surg. 2010;34(9):2155-61.

22. Ng KK, Vauthey JN, Pawlik TM, et al. Is hepatic resection for large or multinodular hepatocellular carcinoma justified? Results from a multiinstitutional database[J]. Ann Surg Oncol. 2005;12(5):364-73.

23. Nojiri K, Tanaka K, Takeda K, et al. The efficacy of liver resection for multinodular hepatocellular carcinoma[J]. Anticancer Res. 2014:34(5):2421-6.

24. Pandey $\mathrm{D}$, Lee $\mathrm{KH}$, Wai $C T$, et al. Long term outcome and prognostic factors for large hepatocellular carcinoma (10 cm or more) after surgical resection[J]. Ann Surg Oncol. 2007;14(10):2817-23.

25. Poon RT, Fan ST, Wong J. Selection criteria for hepatic resection in patients with large hepatocellular carcinoma larger than $10 \mathrm{~cm}$ in diameter[J]. J Am Coll Surg. 2002;194(5):592-602.

26. Wang JH, Changchien CS, Hu TH, et al. The efficacy of treatment schedules according to Barcelona Clinic Liver Cancer staging for hepatocellular carcinoma-survival analysis of 3892 patients[J]. Eur J Cancer. 2008:44(7):1000-6.

27. Yin L, Li H, Li AJ, et al. Partial hepatectomy vs. transcatheter arterial chemoembolization for resectable multiple hepatocellular carcinoma beyond Milan Criteria: a RCT[J]. J Hepatol. 2014;61(1):82-8.

28. Zhong JH, Ke Y, Gong WF, et al. Hepatic resection associated with good survival for selected patients with intermediate and advanced-stage hepatocellular carcinoma[J]. Ann Surg. 2014;260(2):329-40.

29. Zhong $J H$, Xiang BD, Gong WF, et al. Comparison of long-term survival of patients with BCLC stage B hepatocellular carcinoma after liver resection or transarterial chemoembolization[J]. PLoS One. 2013;8(7):e68193.

30. Chang WT, Kao WY, Chau GY, et al. Hepatic resection can provide long-term survival of patients with non-early-stage hepatocellular carcinoma: extending the indication for resection?[J]. Surgery. 2012;152(5):809-20.

31. Huang J, Hernandez-Alejandro R, Croome KP, et al. Hepatic resection for huge $(>15 \mathrm{~cm})$ multinodular HCC with macrovascular invasion[J]. J Surg Res. 2012:178(2):743-50.

32. Ikai I, Yamamoto Y, Yamamoto $N$, et al. Results of hepatic resection for hepatocellular carcinoma invading major portal and/or hepatic veins[J]. Surg Oncol Clin N Am. 2003;12(1):65-75.

33. Pawlik TM, Poon RT, Abdalla EK, et al. Hepatectomy for hepatocellular carcinoma with major portal or hepatic vein invasion: results of a multicenter study[J]. Surgery. 2005;137(4):403-10.

34. Shi J, Lai EC, Li N, et al. Surgical treatment of hepatocellular carcinoma with portal vein tumor thrombus[J]. Ann Surg Oncol. 2010;17(8):2073-80.

35. Torzilli G, Belghiti J, Kokudo N, et al. A snapshot of the effective indications and results of surgery for hepatocellular carcinoma in tertiary referral centers: is it adherent to the EASL/AASLD recommendations?: an observational study of the HCC East-west study group[J]. Ann Surg. 2013; 257(5):929-37.

36. Yang T, Lin C, Zhai J, et al. Surgical resection for advanced hepatocellular carcinoma according to Barcelona Clinic Liver Cancer (BCLC) staging[J]. J Cancer Res Clin Oncol. 2012;138(7):1121-9.

37. Liu L, Miao $R$, Yang $H$, et al. Prognostic factors after liver resection for hepatocellular carcinoma: a single-center experience from China[J]. Am J Surg. 2012;203(6):741-50.

38. Chan SL, Mo FK, Johnson PJ, et al. New utility of an old marker: serial alpha-fetoprotein measurement in predicting radiologic response and survival of patients with hepatocellular carcinoma undergoing systemic chemotherapy[J]. J Clin Oncol. 2009;27(3):446-52.

39. Zhong JH, You XM, Lu SD, et al. Historical comparison of overall survival after hepatic resection for patients with large and/or multinodular hepatocellular carcinoma[J]. Medicine (Baltimore). 2015;94(35):e1426.

40. Feo F, Pascale RM. Multifocal hepatocellular carcinoma: intrahepatic metastasis or multicentric carcinogenesis?[J]. Ann Transl Med. 2015:3(1):4

41. Shah SA, Greig PD, Gallinger S, et al. Factors associated with early recurrence after resection for hepatocellular carcinoma and outcomes[J]. J Am Coll Surg. 2006;202(2):275-83
42. Llovet JM, Bru C, Bruix J. Prognosis of hepatocellular carcinoma: the BCLC staging classification[J]. Semin Liver Dis. 1999;19(3):329-38.

43. Imamura H, Seyama Y, Kokudo N, et al. One thousand fifty-six hepatectomies without mortality in 8 years[J]. Arch Surg. 2003;138(11):1198-206.

44. Ishizawa T, Hasegawa K, Aoki T, et al. Neither multiple tumors nor portal hypertension are surgical contraindications for hepatocellular carcinoma[J]. Gastroenterology. 2008;134(7):1908-16.

45. Cheng HY, Wang $X$, Chen $D$, et al. The value and limitation of transcatheter arterial chemoembolization in preventing recurrence of resected hepatocellular carcinoma[J]. World J Gastroenterol. 2005;11(23):3644-6.

46. Ramsey DE, Kernagis LY, Soulen MC, et al. Chemoembolization of hepatocellular carcinoma[J]. J Vasc Interv Radiol. 2002;13(9 Pt 2):S211-21.

47. Kaibori M, Tanigawa N, Matsui $Y$, et al. Influence of transcatheter arterial chemoembolization on the prognosis after hepatectomy for hepatocellular carcinoma in patients with severe liver dysfunction[J]. Anticancer Res. 2006;26(5B):3685-92

48. Naugler WE, Alsina $A E$, Frenette $C T$, et al. Building the multidisciplinary team for management of patients with hepatocellular carcinoma[J]. Clin Gastroenterol Hepatol. 2015;13(5):827-35.

49. Jiang $S$, Liu $Y$, Wang $L$, et al. A meta-analysis and systematic review: adjuvant interferon therapy for patients with viral hepatitis-related hepatocellular carcinoma[J]. World J Surg Oncol. 2013:11:240.

50. Chan SL, Mo FK, Johnson PJ, et al. Prospective validation of the Chinese University Prognostic Index and comparison with other staging systems for hepatocellular carcinoma in an Asian population[J]. J Gastroenterol Hepatol. 2011:26(2):340-7.

\section{Submit your next manuscript to BioMed Central and we will help you at every step:}

- We accept pre-submission inquiries

- Our selector tool helps you to find the most relevant journal

- We provide round the clock customer support

- Convenient online submission

- Thorough peer review

- Inclusion in PubMed and all major indexing services

- Maximum visibility for your research

Submit your manuscript at www.biomedcentral.com/submit
) Biomed Central 